Bazzini, D. G., \& Shaffer, D. R. (1995). Investigating the social-adjustive and value-expressive functions of wellgrounded attitudes: Implications for change and for subsequent behavior. Motivation and Emotion, 19(4): 279-305. (Dec 1995) Published by Springer Verlag (ISSN: 0146-7239). The original publication is available at www.springerlink.com.

\title{
Investigating the Social-Adjustive and Value- Expressive Functions of Well-Grounded Attitudes: Implications for Change and for Subsequent Behavior
}

\author{
Doris G. Bazzini and David R. Shaffer
}

\begin{abstract}
Recent demonstrations of the plausibility of functional theories of persuasion have occurred within advertising contexts or have targeted potentially nebulous or uninvolving attitudes, and may thus have demonstrated the utility of functional explanations of attitude formation rather than attitude change. In the present study, attitudes that participants have acted on and consider important (i.e., the criteria they use to select dating partners) were the targets of persuasion. High and low self-monitoring individuals, who hold different dating attitudes that serve different functions, were exposed to functionally relevant or functionally irrelevant messages that reached either proattitudinal or counter attitudinal conclusions. As anticipated by functional theory, (a) low self-monitoring individuals changed their dating attitudes only after hearing a counter attitudinal message that addressed the value-expressive functions their dating attitudes served, whereas (b) high self-monitoring individuals changed their opinions only after hearing a counter attitudinal message that addressed the social-adjustive functions served by their dating attitudes. Although the data revealed that important attitudes can be changed via a functionally relevant appeal, only the low self-monitoring individuals subsequently used their changed attitudes to guide their behavior in a subsequent couple-matching task. Implications of these results for functional theories of persuasion and for variations in attitude/behavior consistency were discussed.
\end{abstract}


The functional approach to the study of attitude formation and change addresses the crucial issue "Why do individuals form attitudes and why do they hold the attitudes they do?" Functional theories (Katz, 1960; Smith, Bruner, \& White, 1956) maintain that attitudes serve individual needs and/or enable the individual to execute plans successfully and accomplish important goals. Among the different purposes, or functions, that an attitude might serve are (a) an ego-defensive function, in which one's attitude is held to protect oneself from threatening or undesirable truths; (b) a knowledge ( or object-appraisal) function, in which one's attitude provides a structure for interpreting the meaning of an attitude object; (c) a valueexpressive function, in which the attitude is a reflection of one's important values; and (d) a social-adjustive function, in which one's attitude is held because it assists the individual to adapt successfully to various social situations and/or to behave in ways considered important by various reference groups (Katz, 1960; Smith et al., 1956) Of course, an attitude might serve more than one function, and to some extent, most attitudes serve a knowledge or object-appraisal function (Tesser \& Shaffer, 1990).

All functional theories assume that attitude change is unlikely to occur unless individuals learn that their current attitudes are no longer serving the particular function(s) they were intended to serve (e.g., Katz, 1960; Smith et al., 1956). Yet, attempts to use a persuasion paradigm to validate this proposition have been slowed by the difficulty of identifying a priori the functional underpinnings of individuals' attitudes. Snyder and DeBono (1985) have suggested that attitudes may often serve contrasting functions for people who differ in self-monitoring. High self-monitoring individuals typically attempt to tailor their behavior to the social/interpersonal requirements of the situations they encounter, so as to fit in with others, thus implying that they may often hold attitudes that serve a social-adjustive function. By contrast, low self-monitoring individuals are less inclined to tailor their conduct to social/situational standards of appropriateness. Instead, they tend to rely on internal sources of information (e.g., principles and values) to guide their conduct, thus implying that they may often form attitudes that reflect their underlying values and serve a value-expressive function. In a series of studies assessing participants' responses to advertisements, Snyder and DeBono (1985) found that high self-monitoring individuals were influenced more by image-oriented "soft-sell" ads that implied a product's utility at helping its users to fit in with others (i.e., social-adjustive concerns), whereas low self-monitoring individuals were much more responsive to "hard-sell" ads that focused on the intrinsic quality and value of the products (said to reflect value-expressive concerns).

These findings prompted DeBono (1987) to design a direct test of the functional theory premise that messages addressing the functional underpinnings of recipients' attitudes should be more persuasive than other messages advocating the same conclusion but addressing other goals or motives. High and low self-monitoring individuals who favored deinstitutionalization of the mentally ill listened to either of two counterattitudinal messages that made either value-expressive or social-adjustive concerns especially salient. The value-expressive message noted that favorable attitudes toward institutionalizing the mentally ill (the counterattitudinal position) were held by 
people who valued being "a responsible and loving person" (values that message recipients considered highly important), whereas favorable attitudes toward deinstitutionalization (i.e., recipients' initial attitudes) were held by people who valued being "a courageous and imaginative person" (values that message recipients viewed as relatively unimportant). By contrast, the social-adjustive message noted that a substantial majority of college students (70\%) clearly favored institutionalizing the mentally ill (the counterattitudinal position), whereas only $23 \%$ had favorable attitudes toward de institutionalization (the recipients' initial attitude). As anticipated, DeBono found that low self-monitoring individuals adopted a more favorable attitude toward institutionalizing the mentally ill after hearing the value-expressive (but not the social-adjustive) message, whereas high selfmonitoring individuals were similarly persuaded by the social-adjustive (but not the value-expressive) message. Clearly these findings were consistent with the functional theory premise that functionally relevant appeals which explicitly undermine the utility of recipients' initial attitudes are likely to be much more persuasive than other similar messages that are irrelevant to the functions attitudes serve (see also DeBono \& Harnish, 1988).

DeBono's clever and creative program of research has clearly demonstrated the plausibility of functional explanations of persuasion in particular, and has helped to spark a more general revival of interest in the motivational underpinnings of attitudes (see also Abelson \& Prentice, 1989; Herek, 1987; Shavitt, 1989). Nevertheless, we suspect that the initial attitudes of DeBono's research participants (i.e., attitudes toward deinstitutionalization of the mentally ill or toward the value of a school calendar featuring scantily clad porn-porn girls) probably qualified as "nonattitudes" (Converse, 1970)-that is, nebulous evaluations of the attitude object that participants can report if asked to do so, but are backed by little, if any, issue-relevant knowledge or experience, and are of minimal importance to participants' lives. In other words, it is likely that DeBono has demonstrated (and demonstrated well) the utility of functional explanations of attitude formation rather than attitude change. Could one really alter well-established attitudes that participants hold, have acted on, and consider important, via a functionally relevant appeal? And if such attitudes can be altered, will these changed attitudes have any implications for participants' subsequent behavior? These are two issues that we explore in the present research.

\section{Selection of a Target Issue}

To address the above questions, we searched for a target issue for which participants hold initial attitudes that (a) they have acted on and consider important, and (b) likely serve different functions for different individuals. One such issue that seemed quite promising centered on dating attitudes; specifically, on attitudes concerning the criteria one might use to select compatible dating partners. In a pretest conducted by the second author for an unrelated project exploring the parameters of attitude strength, participants rated (on 9-point scales) strength-related parameters of their attitudes toward "selecting compatible dating partners" and toward 
"deinstitutionalization of the mentally ill." These pretest participants rated their "dating" attitudes to be significantly more important $(M=7.31$,$) more$ stable $(M=6.98)$, and based on more personal knowledge $(M=6.76)$ and behavioral experience $(M=7.43)$ than their attitudes toward "deinstitutionalization of the mentally ill" (Ms $=1.97,2.27,2.03,1.17$, respectively, for attitude importance, stability, knowledgeability, and experience); for all $F(l, 76)>117.50, p<.0001$. So for our population at least, attitudes about date selection are seemingly stronger, or more important, than the target attitudes investigated earlier by DeBono (1987).

Prior research reveals that high and low self-monitoring individuals have highly divergent orientations toward dating relationships (Snyder \& Simpson, 1984), particularly with regard to the use of physical attractiveness as a criterion for date selection (Snyder, Berscheid, \& Glick, 1985). Snyder et al. (1985) for example, found that high self-monitoring individuals pay much more attention to the physical appearance of potential dating partners than do low self-monitoring individuals, who, in turn, devote relatively more attention to dating partners' dispositional attributes (e.g., sociability, openness; see also Glick, 1985). Indeed, the differing criteria that high and low self-monitoring individuals use to select their own dating partners apparently affect their beliefs about how other people should choose their partners. Glick, Demorest, and Hotze (1988), for example, gave participants photographs and personality information about 5 men and 5 women and asked them to form, from these 10 individuals, the 5 couples that they thought would be most compatible. For each of the five male stimulus persons, there was one female target of a similar level of rated physical attractiveness and a second female target whose personality was similar to his own. The results were clear: High self-monitoring individuals were more likely to match couples on the basis of physical attractiveness than were low self-monitoring individuals, who, in tum, were more inclined to use personality information when making their matches.

Prior to conducting our research, we asked 99 introductory psychology students to respond to the Self-Monitoring Scale (Snyder \& Gangestad, 1986) and to a 9-point item which asked ' II things considered, I think

is the more important in my own personal selection of dating partners" $\overline{(1}=$ personality more important; $5=$ personality and attractiveness equally important; $9=$ attractiveness more important). Consistent with past research (e.g., Snyder et al., 1985), high self-monitoring individuals' responses differed from those of low self-monitoring individuals, $F(l, 97)=$ $9.14, p<.001$. Specifically, high self-monitoring individuals said they considered attractiveness information more important than personality when selecting dates $(M=5.67)$, whereas low self-monitoring individuals considered personality information more important for date selection than attractiveness information $(M=4.15)$. 


\section{THE PRESENT STUDY}

Given what is known about the criteria that high and low self-monitoring individuals consider most salient when selecting dating partners, we designed an experiment to determine whether these well-formed and seemingly important initial attitudes might be altered, in accordance with the prescriptions for change suggested by functional theories of attitudes. High self-monitoring individuals, who weigh physical appearance highly when selecting dating partners, may do so in part for social-adjustive reasons (i.e., to enhance their social images). Accordingly, the type of message that might be most effective at inducing them to change their attitudes is a well-reasoned counterattitudinal appeal suggesting that their "attractiveness criterion" is not serving its social-adjustive function and that the use of other criteria (e.g., weighing personality information more heavily) is likely to have positive social benefits and/or enhance peer acceptance. However, a message containing the same persuasive argumentation but stressing a functionally irrelevant (i.e., value-expressive) theme should have little impact on the dating attitudes of high self-monitoring individuals.

By contrast, low self-monitoring individuals are concerned with establishing long-term compatibility in their relationships (Snyder \& Simpson, 1984) and, in keeping with their focus on such values as guidelines for behavior, they weigh dispositional information more heavily than attractiveness when selecting dating partners (Glick, 1985; Snyder et al., 1985).

Thus, the type of message that should be most effective at inducing low self-monitoring individuals to change their dating attitudes is a well-reasoned, value-expressive appeal arguing that (a) values they hold in high esteem are the ones most closely associated with using attractiveness as a primary criterion for date selection, whereas (b) values they consider of lesser importance are the ones most closely associated with selecting dating partners on the basis of dispositional (personality) attributes.

In the present study, then, individuals who differed in self-monitoring propensities each listened to a persuasive message that was either proattitudinal or counterattitudinal for them and was either social-adjustive or value-expressive in its functional orientation. The following conceptual hypotheses were evaluated:

1. High selfmonitoring individuals exposed to a message that is both functionally relevant to them and counterattitudinal (i.e., a social adjustive message touting personality as a criterion for date selection) will express more favorable attitudes toward the use of personality as a selection criterion and less favorable attitudes toward the use of attractiveness information than will their dispositional counterparts exposed to the functionally irrelevant (i.e., value-expressive) counterattitudinal message or to either of the pro attitudinal (Le., proattractiveness) appeals, regardless of their functional relevance.

2. Low self-monitoring individuals exposed to a message that is both functionally relevant to them and counterattitudinal (i.e., a value-expressive message touting attractiveness as a dating criterion) will express less favorable 
attitudes toward the use of personality information and more favorable attitudes about use of attractiveness cues to select dating partners than will their dispositional counterparts exposed to the functionally irrelevant (Le., social-adjustive) counterattitudinal message or to either of the proattitudinal (i.e., propersonality) messages, regardless of their functional relevance.

We also hoped to further extend previous research by determining whether any functionally induced attitude change that our participants displayed would have implications for their subsequent behavior. Toward this end, participants later performed a couple-matching task, modeled after that of Glick et al. (1988). We predicted that when matching male and female stimulus persons as dating partners:

3. High self-monitoring individuals exposed to a message that was both functionally relevant and counterattitudinal for them (i.e., a social-adjustive/ propersonality appeal), will place more weight on personality attributes and less weight on attractiveness information than would their high self-monitoring counterparts who had been exposed to the other three persuasive messages.

4. Low self-monitoring individuals exposed to the message that was both functionally relevant and counterattitudinal for them (i.e., a value-expressive/ proattractiveness appeal) will place more weight on attractiveness information and less weight on personality information than would their low self-monitoring counterparts who had been exposed to the other three persuasive messages.

\section{METHOD}

\section{Participants}

Early in the academic term, a large number of introductory psychology students at the University of Georgia participated in a group testing session during which they completed the Self-Monitoring Scale (Snyder \& Gangestad, 1986) and the instrumental-values section of Rokeach's (1968) value survey. On the basis of a median split of their responses to the SelfMonitoring Scale, half the participants were classified as high self-monitoring individuals (scores;;,; 9) and half as low self-monitoring individuals (scores ::E; 8). Moreover, only participants who had listed the values responsible and loving as relatively important to them (i.e., in the top 6 of the 16 instrumental values), and the values courageous and imaginative as relatively unimportant (i.e., in the bottom 8 of the 16 instrumental values), were selected to participate. There were no significant differences in the average rankings of these values by high and low self-monitoring individuals. One hundred thirty-nine participants (70 male and 69 female) subsequently took part in the experiment for course credit. 


\section{Procedure}

Participants reported and were run individually in an experiment entitled "Dating Relationships." Each participant was told that the psychology department was recently visited by Dr. Jack Stevenson, a renowned psychologist from the University of North Carolina, who specialized in the study of dating relationships. They were further informed that Stevenson had recently completed a survey of the dating activities and preferences of approximately 2400 male and female college students in the Southeast and had described the major results of his research in an interview with the experimenter. Participants were told that they would be asked to listen to this interview and to provide their reactions to the results of the survey; reactions described as potentially important since Stevenson had not sampled from the University of Georgia in conducting his research.

The experimenter, who was unaware of participants' self-monitoring scores, then randomly assigned the participant to hear one of four messages created by variations in message theme (social-adjustive vs. value-expressive) and message direction (propersonality vs. proattractiveness as a criterion for date selection). In all four of these tape-recorded interviews, Stevenson began by describing the methods he used (including use of a polygraph to help ensure that participants' responses would be truthful) when questioning students about the criteria they considered most important in selecting their dating partners. Stevenson then noted that survey respondents fell into two general categories: (a) those who used physical attractiveness information as their primary criterion for date selection and (b) those who thought personality information about prospective dates was the more important criterion for selecting dating partners. At this point, Stevenson noted that he did not view the use of one or the other of these criteria as any "better" or "more mature"; in fact, he proceeded to list five strong arguments that some survey respondents had provided for using physical attractiveness as their primary criterion for picking compatible partners (e.g., ')|ttractiveness, not personality, is what keeps the spark in a relationship; if you are not physically attracted to a dating partner, the relationship can't grow ... and may become boring") and five strong arguments given by other respondents for relying on personality information in their search for compatibility (e.g., "Intelligence, sense of humor, and kindness is what keeps a relationship going; in the long run personal compatibility is important-looks fade, personality doesn't.") Pretesting had revealed that college undergraduates considered the five propersonality arguments and the five pro attractiveness arguments equally strong justifications for their respective positions ( $M s=5.87$ and 5.69 , respectively, on a 7-point scale ranging from 1 (weak argument) to 7 (strong argument), $F$ $<1$, ns.

At this point, the content of the taped interview diverged to effect the variations in message theme and message direction.

Value-Expressive Messages. Participants assigned to hear a value-expressive message listened as Stevenson proceeded to describe who it was that tended to select dates on the basis of one particular criterion and how they 
differed from individuals who used the other criterion. The content of these messages varied depending on the direction the message took. In the value-expressive/proattractiveness message, Stevenson's data revealed that those who select dates on the basis of physical attractiveness information clearly value being a "loving" and "responsible" person (values that participants had rated highly). Stevenson went on to say that these people realize that it is much easier to act on one's values and be loving, committed, and responsible to a partner if one is physically attracted to him or her. By contrast, he reported that those who select dates on the basis of personality information value being very "creative" and highly "imaginative" persons (values that participants had rated as being of little importance). Participants exposed to the value-expressivelpropersonality message heard Stevenson report that those who use personality information to select dating partners clearly value being a "loving" and "responsible" person, and he continued by saying that these people realize that looks may fade and that it is easier to remain committed, loving, and responsible when one's partner displays interests and personality characteristics that are in tune with one's own. By contrast, Stevenson noted that those who select dates on the basis of physical attractiveness information are individuals who highly value being a "courageous" and "imaginative" person.

Social-Adjustive Messages. Instead of learning which values were associated with the use of attractiveness information and personality information as criteria for date selection, participants assigned to hear a social-adjustive message listened as Stevenson provided a consensus cue to describe what the strong majority of their college-age peers considered most important in selecting compatible dates. Stevenson prefaced his remarks by assuring the interviewer that his data were reliable, representative of the student bodies from which he sampled, and almost certainly valid since answers were given while survey respondents were hooked up to a polygraph. Participants exposed to the social-adjustivelproattractiveness message heard Stevenson report that nearly $86 \%$ of his sample said that they used physical attractiveness as a primary criterion for selecting compatible dating partners, whereas $11 \%$ said they used personality information as a primary criterion for date selection, and $3 \%$ reported that personality and attractiveness information were equally important. Participants exposed to the social-adjustivelpropersonality message heard Stevenson report that $86 \%$ of his sample favored personality information as a primary criterion for date selection, whereas $11 \%$ relied most heavily on physical attractiveness information, and 3\% reported that these two criteria were equally important. (See Appendix for transcriptions of the four persuasive messages.)

After Stevenson had described his results, couched in either a socialadjustive or a value-expressive way, the interviewer repeated these results aloud, allegedly to make sure that she had them correct for her notes. The interview then concluded with the interviewer thanking Stevenson for his time and then congratulating him on having conducted an interesting piece of research. 


\section{Dependent Measures}

After listening to the tape, the experimenter reiterated that she was interested in assessing participants' reactions to the speaker and his survey. At this point, the participant was asked to complete a brief questionnaire which contained the attitudinal-dependent variables and items designed to assess participants' impressions of the speaker and the importance of his topic. Three 9-point scales served as our attitudinal measures. The first item was a continuum measure which asked ':All things considered, I think is more important in my own personal selection of dating partners." $\overline{(1}=$ personality more important; $5=$ personality and physical attractiveness equally important; $9=$ physical attractiveness more important) The remaining two attitudinal measures asked participants to indicate how important it was to them that their dating partners "be physically attractive", "have a compatible personality" ( $1=$ not at all important; $5=$ somewhat important; 9 = very important). The remaining items on the questionnaire asked participants to indicate, on 9-point scales, (a) the importance they attached to selecting compatible dating partners, (b) the extent to which Stevenson seemed to be an expert on dating relationships, and (c) the extent to which Stevenson seemed to be a credible spokesman (bigger numbers always indicated more of these attributes).

When the participant was finished, the experimenter remarked that in the future, she hoped to get away from assessing students' reactions to dating surveys and to study their actual dating behaviors. Specifically, she hoped to identify the processes by which a romantic relationship might either blossom or wilt from blind dating encounters that she would arrange as part of a full-fledged dating study. The participant was first asked (as a filler task) to peruse a large number of photographs of "volunteers" for this study while the experimenter gathered some other relevant materials for them to examine more carefully.

\section{Couple-Matching Task}

After approximately 10 minutes, the experimenter returned and explained that, thus far, she had enough information on eight volunteers, four male and four female, to know that she was going to select them as the first wave of blind daters for her subsequent dating study. She then explained that she was interested in creating very compatible couples and was soliciting the advice of college-age judges, who were more similar to the volunteers than she was, to assist her with this task. Thus, the participant was asked to form, from these eight stimulus persons, the four couples that he or she personally felt would be most compatible.

Each of the eight 5-inch by 7-inch cards that participants received contained a photo which had previously been rated for physical attractiveness on a 1 (not at all attractive) to IO (extremely attractive) scale by five independent judges ( 2 men and 3 women). Each photo was assigned the average attractiveness rating given it by the judges. For each of the four male targets, there was a female target of a similar level of physical attractiveness. 
No pair matched for attractiveness differed by more than 0.50 scale points on the I0-point scale.

In addition to the photograph, personality information was provided on each card. Each of the target persons had been previously evaluated on a 10-point scale on the attributes "Sense of humor" and "Extraversion" ( 1 = target lacks this attribute; $I O=$ target scores highly on this attribute). The ratings for these dimensions were manipulated to ensure that each male target had a female target who was similar in personality. To avoid suspicion, the matches were not exact. Instead, the matched men and women were equal on one personality dimension and 1 point apart on the other (with two of the "matches" being equal on Sense of Humor and two being equal on Extraversion).

The ratings on these dimensions were further manipulated to ensure that the targets matched on physical attractiveness were notably dissimilar in personality and that targets with similar personalities would be notably dissimilar in their levels of physical attractiveness. Thus, participants who matched targets on the basis of similarity of physical attractiveness would be creating couples with dissimilar personalities, whereas those who matched targets on personality similarities would be creating couples who clearly differed in physical attractiveness.

Once the participant had created what he or she believed to be the four most compatible couples, a funnel-type debriefing began. Overwhelmingly, participants expressed great interest in Stevenson's survey, viewed it as authentic, and were surprised to learn that the interview had been intended as a persuasive communication. Moreover, participants generally perceived the couple-matching task as their attempt to help an older experimenter to create compatible couples for what they described as a "meaningful" or "important" psychology experiment. Only 5 of the 139 participants (and no more than 1 per cell) professed (only after being informed of the fact) that they suspected either that the interview might be intended as a persuasive communication ( $n=3)$ or that the couple-matching task was a test of their reactions to Stevenson's survey $(n=2)$. Caution dictated that we eliminate these suspicious participants, although none of our subsequent conclusions would have had to be altered had we retained these individuals in the sample.

After being fully debriefed, each participant was sworn to secrecy, thanked sincerely for his or her assistance, and dismissed.

\section{RESULTS}

\section{Participants' Impressions of the Speaker and Target Issue}

Three items on the postexperimental questionnaire were included to measure (a) the perceived importance of the target issue to our participants and (b) the perceived credibility and expertise of the spokesperson (Dr. Stevenson). The 2 (Gender) $\times 2$ (Self-monitoring) $\times 2$ (Functional Relevance) $\times 2$ (Message Direction - Proattitudinal or Counterattitudinal) 
ANOVAs of the credibility and the expertise items produced no significant main effects or interactions (all Fs $<2.25$ ). On an absolute basis, participants thought Stevenson to be a highly credible spokesperson $(G M=8.19)$ who possessed considerable expertise $(G M=7.68)$ about dating relationships. An analogous $2 \times 2 \times 2 \times 2$ ANOVA of the perceived importance item revealed that participants considered the target issue (selection of compatible dating partners) to be very important to themselves ( $G M=$ 7.04). The only significant outcome to emerge from this analysis was a main effect for gender, $F(l, 119)=6.42, p<.02$, which reflected the finding that female participants thought the issue of date selection to be more important $(M=7.29)$ than did males $(M=6.80)$.

\section{Attitudinal Judgments}

Participants' responses to the three attitudinal items were summed (after reverse scoring the importance-of-personality item to make it directionally compatible with the other two measures) to form a composite attitudinal index (Cronbach a. $=.79$ ) for which higher scores indicated stronger reliance on physical attractiveness information (and weaker reliance on personality) as criteria for date selection.

An initial 2 (Gender) $\times 2$ (Self-Monitoring) $\times 2$ (Functional Relevance) $\times 2$ (Message Direction) ANOVA of the composite attitudinal index produced a significant main effect for Self-Monitoring, $F(l, 119)=5.29, p<$ .03. Consistent with previous research (e.g., Glick, 1985; Snyder et al., 1985), high self-monitoring individuals expressed more favorable attitudes about using attractiveness cues as criteria for selecting dating partners ( $M$ $=13.54)$ than did low self-Monitoring individuals $(M=12.47)$. However, this main effect was qualified by two-way interactions between Self-Monitoring and Functional Relevance, $F(I, 119)=6.81, P=.01$, and Self-monitoring and Message Direction, $F(I, 119)=14.83, p<.001$. Because our specific predictions involved within-group comparisons for two groups (high and low self-monitoring individuals) known to differ in their attitudes toward use of attractiveness cues and personality information as dating criteria, further analyses of the data were undertaken within the context of the a priori planned contrasts called for by our functional hypotheses.

\section{Low Self-Monitoring Individuals}

It was predicted that low self-monitoring individuals exposed to a message that is both functionally relevant to them and counterattitudinal (i.e., a value-expressive message touting partner attractiveness) would express more favorable attitudes toward the use of attractiveness information as a criterion for date selection (and less favorable attitudes toward the use of personality information) than would their dispositional counterparts who had heard one of the other three messages. 3 This hypothesis was evaluated by a planned contrast (Rosenthal, 1992) for which a weight of +3 was assigned to the mean composite attitude score of participants who heard the value-expressive/pro attractiveness message, and weights of -1 were assigned 
to the mean composite attitude scores of participants who heard each of the other three (i.e., social-adjustive/proattractiveness; value-expressive/ propersonality; social-adjustive/propersonality) messages. This contrast was indeed significant, $F(I, 119)=8.91, P<.01$, thus corroborating the specific functional hypotheses we had formulated (see Fig. 1, Panel A for the condition means), and analogous 1 versus 3 planned contrasts conducted on each of the three items constituting the composite attitudinal index were significant as well (all ts $>1.76, p s<.05$ ). However the residual of this contrast, which was also significant, $F(2,119)=4.94, P<.01$, reflected the finding that low self-monitoring individuals exposed to counterattitudinal (e.g., pro attractiveness ) messages expressed more favorable attitudes toward the use of attractiveness as a criterion for date selection than did low self-monitoring individuals who heard pro attitudinal messages, $F(l, 119)=6.44, p<.05$.

A

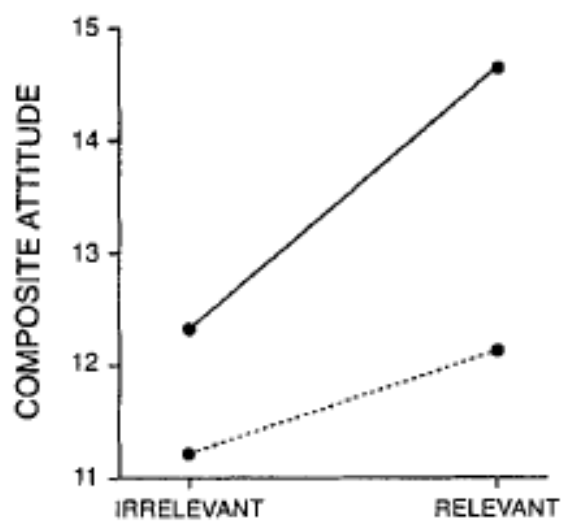

$\bullet$ Counterattitudinal Message

-...... Proattiludinal Message

B

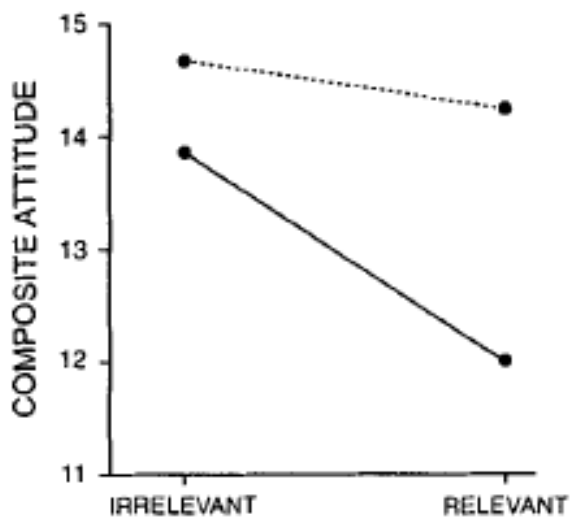

\section{FUNCTIONAL RELEVANCE}

Fig. 1. Mean composite attitude scores (higher numbers represent more favorable attitudes toward use of attractiveness as a criterion for date selection) of low self-monitoring individuals (Panel A) and high self-monitoring individuals (Panel B) who heard proattitudinal or counterattitudinal messages that were functionally relevant or functionally irrelevant for them.

To ensure that our significant planned contrast was not merely capitalizing on this unexpected effect of message direction, we conducted a second a priori planned comparison suggested by functional theory-one that revealed that low self-monitors who heard a functionally relevant (i.e., value-expressive) proattractiveness appeal did express more favorable attitudes toward use of attractiveness information for date selection than did those who heard a functionally irrelevant (i.e., social-adjustive) proattractiveness message, $F(l, 119)=4.24, P<.05$. Indeed, the latter group of 
participants were no more favorable about the use of attractiveness information than were low self-monitors who had heard a functionally relevant but proattitudinal (i.e., value-expressive/propersonality) appeal-a finding that suggests that the counterattitudinal message was not particularly persuasive when it failed to address the value-expressive function that these participants' attitudes serve.

As a final check on the plausibility of our functional hypothesis, we compared our experimental subjects' responses to the continuum item of the composite attitudinal index with those of pretest participants who had completed this same item without ever receiving a persuasive message. The only group of low self-monitoring participants that expressed more favorable attitudes toward the use of attractiveness information $(M=5.31)$ than did the low self-monitoring pretest "controls" $(M=4.15)$ were those who received the value-expressive/proattractiveness message, $t(59)=3.20, P<$ .001. Using pretest subjects' attitudes as a baseline, only the functionally relevant/counterattitudinal message had a significant impact on the attitudes of low self-monitoring individuals-precisely the pattern that functional theory would anticipate.

\section{High Self-Monitoring Individuals}

The specific prediction derived from functional theory was that high self-monitoring individuals exposed to a message that was both functionally relevant for them and counterattitudinal (i.e., a social-adjustive/propersonality message) would express less favorable attitudes toward the use of physical attractiveness as a criterion for date selection (and more favorable attitudes toward the use of personality information) than would their dispositional counterparts in the other three experimental conditions. Examination of Fig. 1 (Panel B) provides some visual support for this prediction. To evaluate its statistical reliability, we conducted a planned contrast for which a weight of -3 was assigned to the mean composite attitude score of high self-monitoring participants who heard the social-adjustive/propersonality message, and weights of +1 were assigned to the mean composite attitude scores of high self-monitoring participants who heard one of the other three (i.e., value-expressive/propersonality; social-adjustive/proattractiveness; value-expressive/proattractiveness) messages. As expected, this contrast was significant, $F(l, 119)=5.91, P<.04$, and its residual was not, $F(2,119)<2.2$, ns.4 Moreover, a second planned comparison suggested by functional theory revealed that high self-monitoring individuals who had heard the functionally relevant (i.e., social-adjustive) propersonality message expressed less favorable attitudes toward the use of attractiveness information as a criterion for date selection than did those who heard a functionally irrelevant (i.e., value-expressive) propersonality message, $F(1,119)=4.29, P<.05$. So, as anticipated by functional theory, the propersonality (i.e., counterattitudinal) message was a more effective persuasive device when it addressed the social-adjustive function that attitudes normally serve for high self-monitoring individuals. 
As a final check on the plausibility of our functional hypothesis, we compared our experimental participants' responses to the continuum item of the composite attitudinal index with those of high self-monitoring pretest participants who had completed this same item without having heard a persuasive message. The only group of high self-monitoring participants that expressed less favorable attitudes toward the use of attractiveness information $(M=4.53)$ than did the high self-monitoring pretest controls $(M=$ 5.67) were those who had heard the social-adjustive/propersonality message, $t(61)=2.18, P<.05$. So consistent with our functional hypothesis, only the message that was both counterattitudinal and functionally relevant had a significant impact on the attitudes of high self-monitoring individuals.

\section{Couple Matching}

Recall that after completing the attitudinal measures and partaking in a filler task for 10 minutes, participants were asked to help the experimenter match couples for a later dating study that she planned to conduct. The four male and four female stimulus persons (SP) that participants were to match were varied in their personality profiles and their levels of physical attractiveness such that each male SP had one female SP who was a close match for level of physical attractiveness and a second female SP whose personality profile was highly similar to his own.

Following the method used by Glick et al. (1988), we computed difference scores between the SPs that participants matched on two dimensions: level of physical attractiveness and similarity of personality profile.

These scores were then averaged across the four couples created by each participant to yield mean difference scores on each of the two dimensions (i.e., physical attractiveness; personality information) that participants might have used to match SPs.

Initial 2 (Gender) $\times 2$ (Self-Monitoring) $\times 2$ (Functional Relevance) $\times 2$ (Message Direction) ANOV As of the Couple Differences scores for physical attractiveness and for personality each yielded a marginally significant main effect for self-monitoring [for attractiveness differences, $F(1,119)$ $=3.63, P<.06$; for personality differences, $F(1,119)=3.44, P<.07]$ that was in line with past research (e.g., Glick et al., 1988). That is, low self-monitoring individuals were somewhat more inclined than their high self-monitoring counterparts to create couples that were similar in personality and dissimilar in attractiveness (Table I). Note, however, that these self-monitoring main effects are marginal only because the analyses included those individuals whose attitudes (and presumably, whose criteria for matching couples) had changed due to their earlier exposure to a functionally relevant/counterattitudinal appeal. Indeed, follow-up ANOV As of participants in the remaining three message conditions produced robust main effects of self-monitoring for each index: for attractiveness differences, $F(l, 94)=10.87, P<$ .001 ; for personality differences, $F(I, 94)=9.42, P<.001$.

In addition to the main effects for Self-monitoring, the ANOVA for each index also produced a significant Functional Relevance $x$ Message Direction interaction effect [for attractiveness differences, $F(I, 119)=4.88$, 
$P<.05$; for personality differences, $F(I, 119)=5.19, p<.05$,] that reflected the finding that participants exposed to a functionally relevant/counterattitudinal appeal were more inclined to match couples on the basis of attractiveness and less inclined to match couples on personality information than were their counterparts in the other three message conditions. This is the pattern that we had anticipated for low self-monitoring but not for high self-monitoring individuals. To further explore the implication of these interactions, we conducted the within-group planned contrasts that permitted more precise tests of our functional hypotheses.

Table I. Mean Differences in Physical Attractiveness and in Personality of Couples Matched by Low and by High Self-Monitoring Individuals Who Heard Different Pro- or Counterattitudinal Messages ${ }^{a}$

\begin{tabular}{|c|c|c|c|c|}
\hline \multirow[b]{3}{*}{ Measure } & \multicolumn{4}{|c|}{ Message received } \\
\hline & \multicolumn{2}{|c|}{ Functionally relevant } & \multicolumn{2}{|c|}{ Functionally irrelevant } \\
\hline & Counterattitudinal & Proattitudinal & Counterattitudinal & Proattitudina \\
\hline \multicolumn{5}{|c|}{ Low self-monitoring individuals } \\
\hline$n$ & 16 & 16 & 18 & 16 \\
\hline \multicolumn{5}{|l|}{$\begin{array}{l}\text { Attractiveness } \\
\text { differences }\end{array}$} \\
\hline$M$ & 3.08 & 4.02 & 4.07 & 3.73 \\
\hline$S D$ & 1.59 & 1.25 & 1.18 & 1.39 \\
\hline \multicolumn{5}{|l|}{$\begin{array}{l}\text { Personality } \\
\text { differences }\end{array}$} \\
\hline$M$ & 4.15 & 2.51 & 2.81 & 3.22 \\
\hline$S D$ & 2.59 & 2.23 & 2.01 & 2.18 \\
\hline \multicolumn{5}{|c|}{ High self-monitoring individuals } \\
\hline$n$ & 16 & 17 & 16 & 18 \\
\hline \multicolumn{5}{|l|}{$\begin{array}{l}\text { Attractiveness } \\
\text { differences }\end{array}$} \\
\hline$M$ & 3.23 & 2.31 & 2.58 & 2.75 \\
\hline$S D$ & 1.22 & 1.26 & 1.23 & 1.08 \\
\hline \multicolumn{5}{|l|}{$\begin{array}{l}\text { Personality } \\
\text { differences }\end{array}$} \\
\hline$M$ & 3.92 & 4.10 & 4.16 & 4.23 \\
\hline$S D$ & 1.97 & 2.06 & 2.19 & 1.75 \\
\hline
\end{tabular}

${ }^{a}$ Larger cell means $=$ larger differences on each attribute.

Matches by Low Self-Monitoring Individuals. We predicted that low selfmonitoring individuals who had heard a functionally relevantlcounterattitudinal (Le., value-expressive/proattractiveness) message would place more weight on attractiveness information and less weight on personality information when matching couples than would their dispositional counterparts who had heard one of the other three persuasive messages. To evaluate these hypotheses, the mean Couple Difference scores for physical attractiveness and for personality profile (shown in Thble I) were subjected to 1 versus 3 planned contrasts. The contrast weights were as follows: weights of +3 (for 
differences in attractiveness) or -3 (for differences in personality) were assigned to the mean difference scores of low self-monitoring participants who heard a functionally relevantlcounterattitudinal (i.e., value-expressive/proattractive ness) message; weights of -1 (for differences in attractiveness) or +1 (for differences in personality) were assigned to the mean difference scores of low self-monitoring participants in the other three message conditions. Consistent with our functional hypotheses, low self-monitoring participants who heard the value-expressive/proattractiveness message did create couples that were more similar in physical attractiveness (1 vs. 3 contrast), $F(I, 119)$ $=5.13, p<.03$; residual $F(2,119)<1$, ns, and more dissimilar in personality (1 vs. 3 contrast), $F(1,119)=4.09, p<.05$; residual contrast, $F(2,117)<$ 1 , ns, than were couples matched by low self-monitoring participants who had heard any of the other messages.

Couples Matched by High Self-Monitoring Individuals. In view of our finding that high self-monitoring individuals who heard a social-adjustive/ propersonality message did express less favorable attitudes about using attractiveness as a dating criterion than their dispositional counterparts who heard other messages, we expected to find that the couples matched by these individuals would be more similar in personality and more dissimilar in attractiveness than couples matched by high self-monitoring individuals in the other experimental conditions. However, neither the pertinent 1 versus 3 contrasts that we computed to test these functional hypotheses nor the residuals of these contrasts approached significance (all Fs $<2$ ). Apparently the functionally induced attitude change we observed for high self-monitoring individuals who heard a social-adjustive/propersonality message had no meaningful implications for their subsequent couplematching behavior.

\section{DISCUSSION}

Evidence is gradually accumulating in support of a key proposition of all functional theories of attitudes, namely, information directly pertinent to the functions attitudes serve will be more persuasive than will data addressing functionally irrelevant objectives. Advertising studies, for example, have shown that participants form more favorable attitudes toward a variety of consumer goods when the ads highlight functionally relevant rather than functionally irrelevant concerns (Shavitt, 1989; Snyder \& DeBono, 1985). Equally impressive support for the functional mediation of persuasion are DeBono's (1987; DeBono \& Harnish, 1988) findings that persuasive appeals are most effective at influencing attitudes when they in some way address the underlying motives that such attitudes serve. Yet, important as these latter demonstrations may be, we suspected that the initial opinions of DeBono's participants (e.g., favoring de institutionalization of the mentally ill) may have been rather weak or nebulous positions (i.e., nonattitudes), thus implying that what DeBono and colleagues (and the advertising studies) have demonstrated is the utility of functional explanations of attitude formation rather than attitude change. So a primary objective of the present research was to determine whether well-established attitudes that participants have acted on and consider important are amenable to change 
via a functionally relevant appeal. A demonstration that such attitudes can be changed would provide important additional support for functional explanations of persuasion.

The present study focused on a target issue (date selection) for which our sample had well-established attitudes that they had acted on and considered important. Moreover, pretesting (and previous research; e.g., Snyder et al., 1985) suggested that although high and low self-monitoring individuals consider the issue of date selection to be equally important, they vary with respect to (a) the specific criteria they weigh more heavily in selecting compatible dating partners (high self-monitoring individuals weighing physical attractiveness more heavily than personality information; low self-monitoring individuals displaying the opposite pattern) and (b) the function served by those dating attitudes (social-adjustive concerns for high self-monitoring individuals; value-expressive concerns for low self-monitoring individuals). Predictions derived from functional theory were straightforward. High self-monitoring individuals should be most inclined to change their dating attitudes after hearing a functionally relevant (Le., social-adjustive) message that challenges their existing position and suggests how the adoption of a new perspective (i.e., weighing personality more heavily) would better serve their objectives. A functionally relevant/counterattitudinal message should also be most persuasive for low self-monitoring individuals. Specifically, these dispositionally guided participants should be more inclined to change their dating attitudes after hearing a value-expressive message that illustrates how using attractiveness as a dating criterion (the counterattitudinal position) is most congruent with important values they hold.

The postmessage attitudinal judgments of our participants were highly consistent with these expectations. Low self-monitoring individuals who heard the value-expressive/proattractiveness message did express more favorable attitudes toward the use attractiveness as a dating criterion and less favorable attitudes toward the use of personality information than did their dispositional counterparts in the other three message conditions. Moreover, low self-monitoring individuals who heard the functionally irrelevant counterattitudinal appeal were apparently not persuaded, as their attitudes toward the use of attractiveness as a dating criterion did not differ from those of their dispositional counterparts who heard proattitudinal (i.e., propersonality) messages. Also, as predicted, high self-monitoring individuals who heard the social-adjustive/propersonality message did come to express less favorable attitudes toward the use of attractiveness as a dating criterion and nominally more favorable attitudes toward the use of personality information than did high self-monitoring individuals who heard other messages. And as we observed for low self-monitoring individuals, high selfmonitoring individuals who heard the functionally irrelevant (i.e., value-expressive) counterattitudinal appeal were apparently not persuaded, for they expressed no less favorable attitudes toward the use of attractiveness as a dating criterion than their dispositional counterparts who heard proattitudinal (i.e., proattractiveness) messages. Taken together, these observations represent an important replication and extension of DeBono's (1987) earlier work: one suggesting that even demonstratively important initial attitudes 
that have likely been used as guidelines for behavior can be changed, as long as the information one receives undermines the functional utility of those attitudes while suggesting how the adoption of a new attitude would better serve one's objectives.

Having observed the patterns of functionally mediated attitude change that were anticipated, we analyzed data from the couple-matching task, seeking to determine if these changed attitudes would have meaningful implications for participants' subsequent behavior. Clearly, it seemed so for low self-monitoring individuals. That is, the low self-monitoring participants who heard the value-expressive/proattractiveness appeal not only expressed more favorable attitudes toward the use of attractiveness as a criterion for date selection (and less favorable attitudes toward the use of personality information) than did their dimensional counterparts who heard other messages, but the couples they subsequently matched differed significantly less in physical attractiveness and significantly more in personality than did couples matched by low self-monitoring individuals in the other three message conditions. So the low self-monitoring participants whose attitudes had changed did seem to behave in accordance with their changed attitudes. By contrast, high self-monitoring individuals who had heard the social-adjustive/ propersonality message showed the anticipated pattern of attitude change (expressing less favorable attitudes toward the use of attractiveness as a dating criterion than their dimensional counterparts who heard other messages), but they were no more inclined to match couples on the basis of personality, nor any less inclined to match on attractiveness information, than were any other group of high self-monitoring participants. Thus, the high self-monitoring individuals who heard a functionally relevant/counterattitudinal appeal appear not to have acted on the basis of their changed attitudes.

Though we did not anticipate this pattern of outcomes for the high self-monitoring participants, perhaps we should have. Over the years, several investigators have found that dispositionally focused low self-monitoring individuals are more likely than situationally focused high self-monitoring individuals to rely on existing attitudes to guide their behavior (cf. Eagly \& Chaiken, 1993; Zanna, Olson, \& Fazio, 1980) either (a) because the attitudes of low self-monitoring individuals are normally more accessible from memory (Kardes, Sanbonmatsu, Voss, \& Fazio, 1986; Shavitt \& Fazio, 1988) and, thus, available to guide one's conduct, or (b) (when attitudes are equally accessible) because dispositionally-focused low self-monitoring individuals perceive their attitudes as more relevant guidelines for behavior (cf. Eagly \& Chaiken, 1993; Snyder \& Kendzierski, 1982). Clearly, our study was not designed to discriminate between these two explanations, and either or both possibilities may have contributed to the dispositional variations in attitudelbehavior consistency that we observed. But whatever the pertinent underlying processes, one contribution of the present study is its demonstration that even when attitudes have recently changed, low self-monitoring individuals are more inclined than their dimensional opposites to use these changed attitudes to guide their conduct. 


\section{APPENDIX}

\section{Persuasive Messages}

\section{Social-Adjustive/Propersonality Message}

Interviewer: That's interesting, it seems that there were quite divergent views among college students. Did either strategy seem to be chosen by a majority of the students?

Dr. Stevenson: I discovered that $11 \%$ of the students surveyed said that physical attractiveness was the most important factor in choosing a date, $3 \%$ had no opinion, an overwhelming $86 \%$ of the students reported that personality of a date was most important.

Interviewer: You're kidding! The majority of the students surveyed based their dating choice selection on personality attributes?

Dr. Stevenson: Apparently so. These individuals reported that although it is said in an initial interaction with a person all you have to go on is looks, anyone who is at all socially sensitive, even in a first-time meeting, can tell if another person is somewhat compatible. Sometimes, even a few words with someone can reveal a lot about him/her; the way he or she looks at you, how much they smile, the amount of eye contact that is maintained, even their body language. Plus, even in a conversation that is a few minutes long, you can find out if he or she is shy or outgoing, or what kinds of interests they have. And what's more interesting is it seems that the general reaction to individuals who chose a partner based on looks was quite negative.

Interviewer: Negative? Why, what did they say?

Dr. Stevenson: Both the men and women surveyed responded that most people are wise to those who use the attractiveness of a date to boost how they themselves look, and they feel that these people are really (as one woman termed them) "geeks." It seems that the majority of college students in the Southeast feel very strongly that people who choose dates primarily on the basis of looks are shallow and transparent. Interviewer: Do those results surprise you?

Dr. Stevenson: No, not really. I think there is a growing trend in our youth which is moving away from the emphasis which the media and other forces in our society place upon external beauty. I think the growing consensus will emphasize that what's on a person's inside is more important than external attributes. 


\section{Social-Adjustive/Proattractiveness Message}

Interviewer: That's interesting, it seems that there were quite divergent views among college students. Did either strategy seem to be chosen by a majority of the students?

Dr. Stevenson: I discovered that $11 \%$ of the students surveyed said that personality was the most important factor in choosing a date, $3 \%$ had no opinion, and an overwhelming $86 \%$ of the students reported that the attractiveness of a date was most important.

Interviewer: You're kidding! The majority of the students surveyed based their dating choice selection on looks?

Dr. Stevenson: Apparently so. These individuals reported that in an initial interaction with a person all you have to go on is looks, and furthermore, in a dating situation most people prefer to be with someone to whom they are attracted. Both the men and the women interviewed admitted that personality is not totally irrelevant, but that it is harder to develop intimacy in a relationship with someone who you do not find physically attractive. With greater physical attraction to a partner comes more intense longing for intimacy, and with greater intimacy comes more long-term satisfaction.

Interviewer: So they feel that if you are physically attracted to your partner it will be easier to overcome some of the obstacles that prevent intimacy and might eventually lead to the breaking-up of the relationship?

Dr. Stevenson: Yes, that's pretty accurate. Particularly when one considers the fact that many relationships dissolve because one of the partners in the relationship is attracted to someone else. If one is to overcome the temptations of being attracted to other members of the opposite sex you must inevitably be physically attracted to your current partner.

Interviewer: Do those results surprise you?

Dr. Stevenson: No, not really. College students, and people in general, seem to adhere to the "Beautiful is good" syndrome, and I don't really see this strong consensus changing anytime soon.

\section{Value-Expressive/ Proattractiveness Message}

Interviewer: So the students were asked "What do you look for in a date?" Were they asked to do or say anything else?

Dr. Stevenson: In addition to being asked what they look for in a date, students were asked to think about (and why don't you yourself do this) "which are the most enduring life-forces or values that are important to you"? They were asked to write down these values and then rank order them. What I was trying to get at was an understanding of why some people choose a date on the basis of looks and others choose on the basis of personality. 
(Remember that students were still hooked up to the polygraph machine so that the possibility of students lying was minimal.) What I found was quite interesting. I found that students who had ranked being responsible and loving among their most important values were the ones who reported that attractiveness in a date was much more important than personality.

Interviewer: Wait a minute. People who had ranked responsible and loving as values that were important to them said that they used looks as a basis for choosing a dating partner?

Dr. Stevenson: Well, when I first got these results I raised my eyebrows a bit too. But after I asked some follow-up questions it made a lot more sense to me. It seems that these individuals are very commitment-oriented. They feel that once they make a commitment they will stick to it and it will last. Relationship stability over time is crucial to such individuals, and since their capacity for love and loyalty is so great, most of their relationships are long term. The fact is, they seem to admit to themselves that in a long term relationship, it is obviously more pleasant to be with someone who is physically appealing. With greater physical attraction to a partner comes more intense longing for intimacy, and with greater intimacy comes more long term satisfaction. The bottom line is that people who value being responsible and loving honestly admit that it is easier to be committed to someone who they find physically attractive.

Interviewer: So they feel that if you are physically attracted to your partner it will be easier to overcome some of the obstacles that prevent intimacy and might eventually lead to the breaking-up of the relationship?

Dr. Stevenson: Yes, that's pretty accurate. Particularly when one considers the fact that many relationships dissolve because one of the partners in the relationship is attracted to someone else. If one is to overcome the temptations of being attracted to other members of the opposite sex you must inevitably be physically attracted to your current partner.

Interviewer: So if people who value being responsible and loving select dates on the basis of looks, which people out there choose on the basis of personality?

Dr. Stevenson: I found that individuals who had ranked the values of being imaginative and courageous as their two most important values used a much different strategy when choosing a date than did the responsible/ loving individuals. These people reported that personality rather than looks was a much greater influence in their dating choice.

Interviewer: Why would wanting to be imaginative and courageous as major life forces necessarily lead individuals to choose a date based on personality attributes?

Dr. Stevenson: They desire a partner who takes risks like themselves and dating selection based on sheer physical appearance simply does not 
provide sufficient evidence of compatibility. For example, an attractive person has learned to get by on looks, probably prefers the status quo, and may not be an attractive date to those impulsive risk-taking individuals who choose on personality.

\section{Value-Expressive/Propersonality Message}

Interviewer: So the students were asked "What do you look for in a date?" Were they asked to do or say anything else?

Dr. Stevenson: In addition to being asked what they look for in a date, students were asked to think about (and why don't you yourself do this) "which are the most enduring life-forces or values that are important to you"? They were asked to write down these values and then rank order them. What I was trying to get at was an understanding of why some people choose a date on the basis of looks and others on the basis of personality. (Remember that students were still hooked up to the polygraph machine so that the possibility of students lying was minimal.) What I found was quite interesting. I found that students who had ranked being responsible and loving among their most important values were the ones who reported that personality in a date was much more important than attractiveness.

Interviewer: What was their reasoning?

Dr. Stevenson: After asking some follow-up questions it seems that these individuals are very commitment-oriented. They feel that once they make a commitment they will stick to it and it will last. Relationship stability over time is crucial to such individuals, and since their capacity for love and loyalty is so great, most of their relationships are long term. The fact is they seem to admit to themselves that looks fade with time and that it is much more important to be with someone who is a nice person, and who has personality characteristics that you'll be able to live with.

Interviewer: So they feel that if you and your partner are compatible and have similar personalities, it will be easier to overcome some of the obstacles that prevent long-term friendship within the relationship from developing.

Dr. Stevenson: Yes, that's pretty accurate. Particularly when one considers the fact that many relationships dissolve because of the lack of communication in the relationship. If one is to make a relationship last, you have to not only love, but really like your partner.

Interviewer: So if people who value being responsible and loving select dates on the basis of personality, which people out there choose on the basis of attractiveness?

Dr. Stevenson: I found that individuals who had ranked the values of being imaginative and courageous as their two most important values used a much different strategy when choosing a date than did the responsible! 
1oving individuals. These people reported that attractiveness rather than looks was a much greater influence in their dating choice.

Interviewer: Why would wanting to be imaginative and courageous as major life forces necessarily lead individuals to choose a date based on physical attributes?

Dr. Stevenson: Apparently people who value being imaginative in particular are very drawn to beauty and to beautiful things. These individuals, who are usually quite free-spirited, often follow their first whim, that is, their first impression of a person. They, therefore, will base most of their dating decisions on what strikes them first about a person, and this usually implies the physical exterior. Those who value courageousness are similar in that they often look for qualities in a partner that are indicative of physical prowess in order to match their own imagined energy and spontaneity. It seems that physical attractiveness and physical prowess are often perceived as one and the same in our society.

\section{NOTES}

3. It is conceivable that a message touting one particular criterion for date selection (e.g., attractiveness) might change the emphasis that participants place on that information without influencing the import of the other (personality) criterion. Methodologically, however, our use of the continuum measure forces participants whose attitudes toward one criterion have changed to weight the other attribute less heavily. Thus, our predictions were dictated in part by our measures.

4. Analogous 1 versus 3 planned contrasts conducted on each of the three items constituting the composite attitudinal index were significant for both the continuum and the importance-of-attractiveness items (both $t s>1.73, p s<.05$ ) but not for the importance-of-personality item, $t<1.5$, ns, although the means were ordered as expected. 


\section{REFERENCES}

Abelson, R. P., \& Prentice, D. A. (1989). Beliefs as possessions: A functional perspective. In A. R. Pratkanis, S. J. Breckler, \& A. G. Greenwald (Eds.), Attitude structure and function (pp. 361-381). Hillsdale, NJ: Erlbaum.

Converse, P. E. (1970). Attitudes and non-attitudes: Continuation of a dialogue. In E. R. Tufte (Ed.), The quantitative analysis of social problems (pp. 168-189). Reading, MA: Addison-Wesley.

DeBono, K. G. (1987). Investigating the social-adjustive and value-expressive functions of attitudes: Implications for persuasion processes. Journal of Personality and Social Psychology, 52, 279-287.

DeBono, K. G., \& Harnish, R. J. (1988). Source expertise, source attractiveness, and the processing of persuasive information: A functional approach. Journal of PeTYonality and Social Psychology, 55, 541-546.

Eagly, A. H., \& Chaiken, S. (1993). The psychology of attitudes. Fort Worth, TX: Harcourt Brace Jovanovich.

Glick, P. (1985). Orientations toward relationships: Choosing a situation in which to begin a relationship. Journal of Experimental Social Psychology, 21, 544-562.

Glick, P., DeMorest, J. A., \& Hotze, C. A. (1988). Self-monitoring and beliefs about partner compatibility in romantic relationships. PeTYonality and Social Psychology Bulletin, 14, 485-494.

Herek, G. M. (1987). Can functions be measured? A new perspective on the functional approach to attitudes. Social Psychology Quarterly, 50, 285-303.

Kardes, F. R., Sanbonmatsu, D. M., Voss, R. T., \& Fazio, R. H. (1986). Self-monitoring and attitude accessibility. Personality and Social Psychology Bulletin, 12, 468-474.

Katz, D. (1960). The functional approach to the study of attitudes. Public Opinion Quarterly, 24, 163-204.

Rokeach, M. (1968). Beliefs, attitudes, and values: A theory of organization and change. San Francisco: Jossey-Bass.

Rosenthal, R. (1992). Computing contrasts: On sharpening psychological science. In R. F. Baumeister \& D. M. Tice (Eds.), Dialogue of the society for personality and social psychology (p. 3) Cleveland, OH: Society for Personality and Social Psychology.

Shavitt, S. (1989). Operationalizing functional theories of attitude. In A. R. Pratkanis, S. J. Beckler, \& A. G. Greenwald (Eds.), Attitude structure and function (pp. 311-338). Hillsdale, NJ: Erlbaum.

Shavitt, S., \& Fazio, R. H. (1988). Attitude functions and self-monitoring in the attitude-behavior relation. Paper presented at the annual meeting of the Midwestern Psychological Association, Chicago. 
Smith, M. B., Bruner, J. S., \& White, R. W. (1956). Opinion and personality. New York: Wiley.

Snyder, M., \& DeBono, K. G. (1985). Appeals to images and claims about quality: Understanding the psychology of advertising. Journal of Personality and Social Psychology, 49, 586-597.

Snyder, M., \& Gangestad, S. (1986). On the nature of self-monitoring: Matters of assessment, matters of validity. Journal of Personality and Social Psychology, 51, 125-139.

Snyder, M., \& Kendzierski, D. (1982). Acting on one's attitudes: Procedures for linking attitudes and behavior. Journal of Experimental Social Psychology, 18, 165-183.

Snyder, M., \& Simpson, J. A. (1984). Self-monitoring and dating relationships. Journal of Personality and Social Psychology, 47, 1281-1291.

Tesser, A., \& Shaffer, D. R. (1990). Attitudes and attitude change. Annual Review of Psychology, 41, 479-523.

Zanna, M. P., Olson, 1. M., \& Fazio, R. H. (1980). Attitude-behavior consistency: An individual difference perspective. Journal of Personality and Social Psychology, 38, 432-440. 